\title{
MODEL PENENTUAN TARIF MENGGUNAKAN MINIMISASI BIAYA DAN PERMINTAAN INPUT UNTUK PERUSAHAAN MONOPOLI
}

\author{
Fitrawaty \\ Fakultas Ekonomi Universitas Negeri Medan \\ Jl. Williem Iskandar Ps. V Medan 20221, Telp. 061-6613365 \\ Email: fitra53@gmail.com
}

\begin{abstract}
Provision of some public goods, such as drinking water, electricity, gas, telephone, in many countries is generally done by the government. This is due to the firm is a natural monopoly, meaning that these companies require a huge investment, so that the level of efficiency can be achieved when the large scale of production. The problem is what price should be charged to the public? This study aimed to determine the price of a good in theory. The method used is minimization cost of production (through indirect cost function) with the constraints of the production function.
\end{abstract}

Key words: Minimum Cost, Price, Monopolistic

\section{PENDAHULUAN}

truktur pasar menggambarkan tingkat persaingan di suatu pasar. Biasanya pasar dikelompokkan menjadi empat, yaitu: pasar persaingan sempurna, persaingan monopolistik, monopoli dan oligopoly. Struktur pasar ditentukan oleh beberapa unsur (Arsyad, 1995 : 323), antara lain: (1) Pengaruh karakteristik produk. Karakteristik suatu produk biasanya mempengaruhi struktur pasar di mana produk tersebut diperjual belikan. Jika produk-produk lain merupakan produk pengganti (substitute) yang baik, maka tingkat persaingan akan semakin ketat, (2) Pengaruh fungsi produksi.Sifat fungsi produksi merupakan faktor penentu struktur pasar yang paling fundamental. Industri yang fungsi produksinya menunjukkan keadaan increasing return to scale yang outputnya relatif besar dibanding dengan permintaan totalnya biasanya jumlah produsen akan lebih sedikit sehingga tingkat persaingannya lebih ringan, (3) Pengaruh pembeli. Jika di pasar hanya ada sedikit pembeli, maka tingkat persaingan akan semakin rendah daripada yang pembelinya banyak.

Menurut Nicholson (1992: 360), suatu perusahaan monopoli bisa timbul karena dua jenis hambatan, yaitu hambatan teknis dan hambatan hukum (technical and legal barriers). Hambatan teknis seperti penguasaan faktor produksi strategis dan terbatasnya pasar. Sedangkan hambatan hukum seperti pemberian hak paten (patent 
right) atau hak cipta dan pemberian hak monopoli oleh pemerintah seperti BUMN dan BUMD.

Dalam pasar monopoli, permintaan terhadap output perusahaan merupakan permintaan industri. Karena itu perusahaan mempunyai kemampuan untuk mempengaruhi harga pasar (price setter) dengan mengatur jumlah output. Jadi perusahaan monopoli dapat menentukan berapa banyak output yang harus dijual serta pada tingkat harga berapa agar memperoleh keuntungan maksimum.

Penyediaan beberapa barang publik, seperti air minum, listrik, gas, telepon, di banyak negara umumnya dilakukan oleh pemerintah. Hal ini disebabkan perusahaan tersebut biasanya bersifat monopoli alamiah (natural monopoly), artinya perusahaan ini memerlukan biaya investasi yang cukup besar sehingga tingkat efisiensi baru dapat dicapai bila skala produksinya besar (large scale of production). Yang sering menjadi permasalahan adalah berapa tarif air yang seharusnya dikenakan ke masyarakat? Kajian ini akan membahas penentuan tarif dari perusahaan monopoli secara teori.

\section{KAJIAN TEORI}

Menurut Miller dan Meiners (1994:249), produksi diartikan sebagai penggunaan atau pemanfaatan sumberdaya yang mengubah suatu komoditi menjadi komoditi lainnya yang sama sekali berbeda baik dalam pengertian apa, dan di mana atau kapan komoditi-komoditi itu dialokasikan maupun dalam pengertian apa yang dapat dikerjakan oleh konsumen terhadap komoditi itu.

Fungsi produksi memungkinkan input-input dikombinasikan dengan berbagai jumlah output. Fungsi produksi juga menggambarkan apa yang layak secara teknis (technically fisible) bila perusahaan beroperasi secara efisien, yaitu apabila perusahaan menggunakan setiap kombinasi input seefektif mungkin, ini berarti bahwa input tidak akan digunakan bila menurunkan output (Pindyck dan Rubinfeld,1998 : 132).

Tambahan output yang dihasilkan dari penambahan satu input dimana input lain konstan disebut produksi marginal (Marginal Physical Product, MP) dari input tersebut. Hubungan antara MP, produksi total (Total Physical Product, TP) dan produksi rata-rata (Average Physical Product,AP) dapat dijelaskan pada Gambar 1.

A adalah titik belok (inflection point) dimana MP maksimum, B adalah titik dimana AP mencapai maksimum, $C$ adalah titik dimana TP maksimum dan MP sama dengan nol. Daerah yang ekonomis untuk berproduksi adalah daerah II (dari B hingga C).

Kemajuan teknologi dapat membuat tingkat produktifitas meningkat. Secara grafis dapat digambarkan dengan semakin luasnya bidang yang dibatasi oleh kurva TP seperti pada Gambar 2, dimana jumlah output yang dihasilkan per unit faktor produksi semakin besar. 


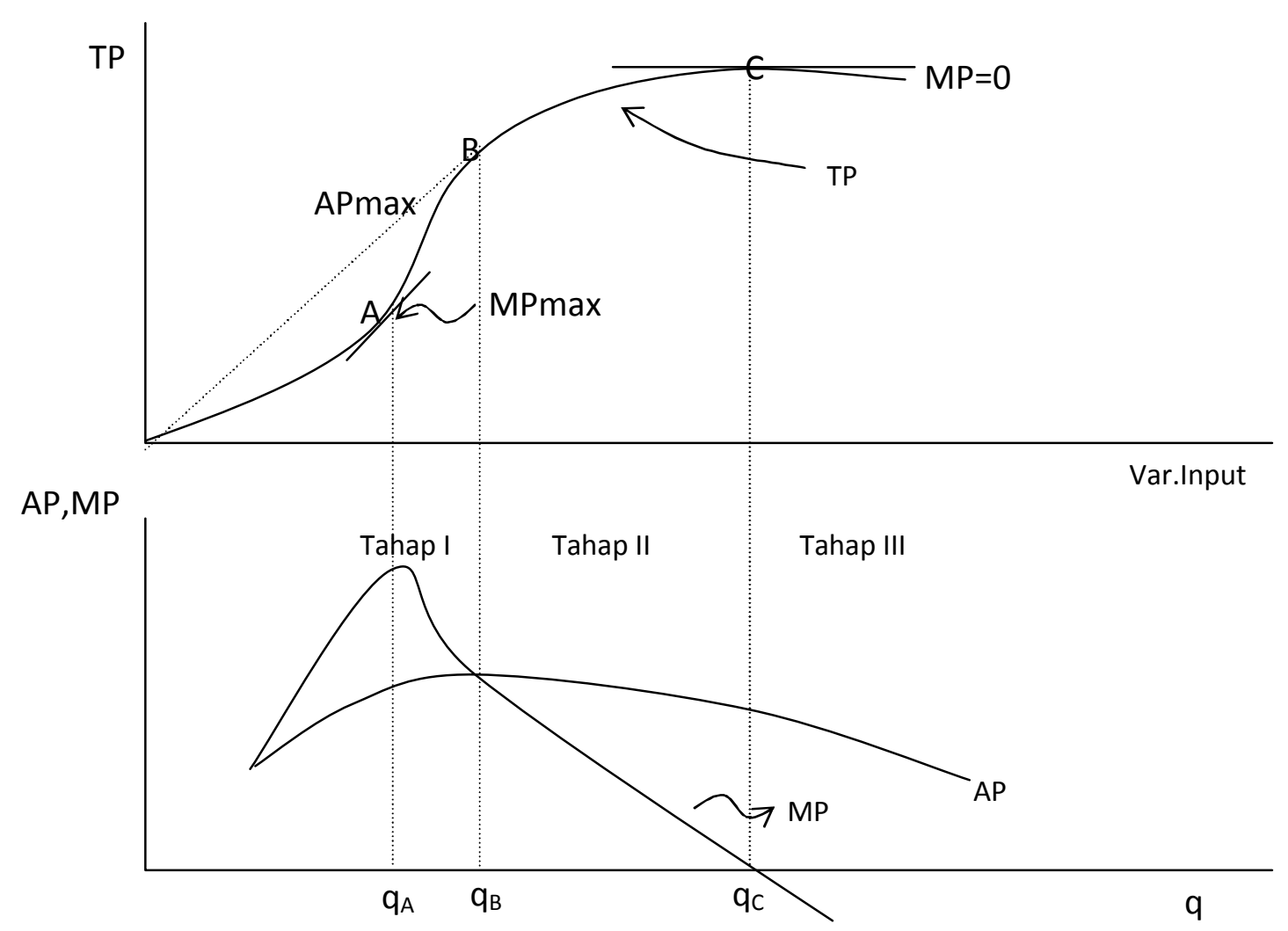

Sumber : Salvatore, $2002: 248$

Gambar 1. Hubungan antara MP, TP dan AP

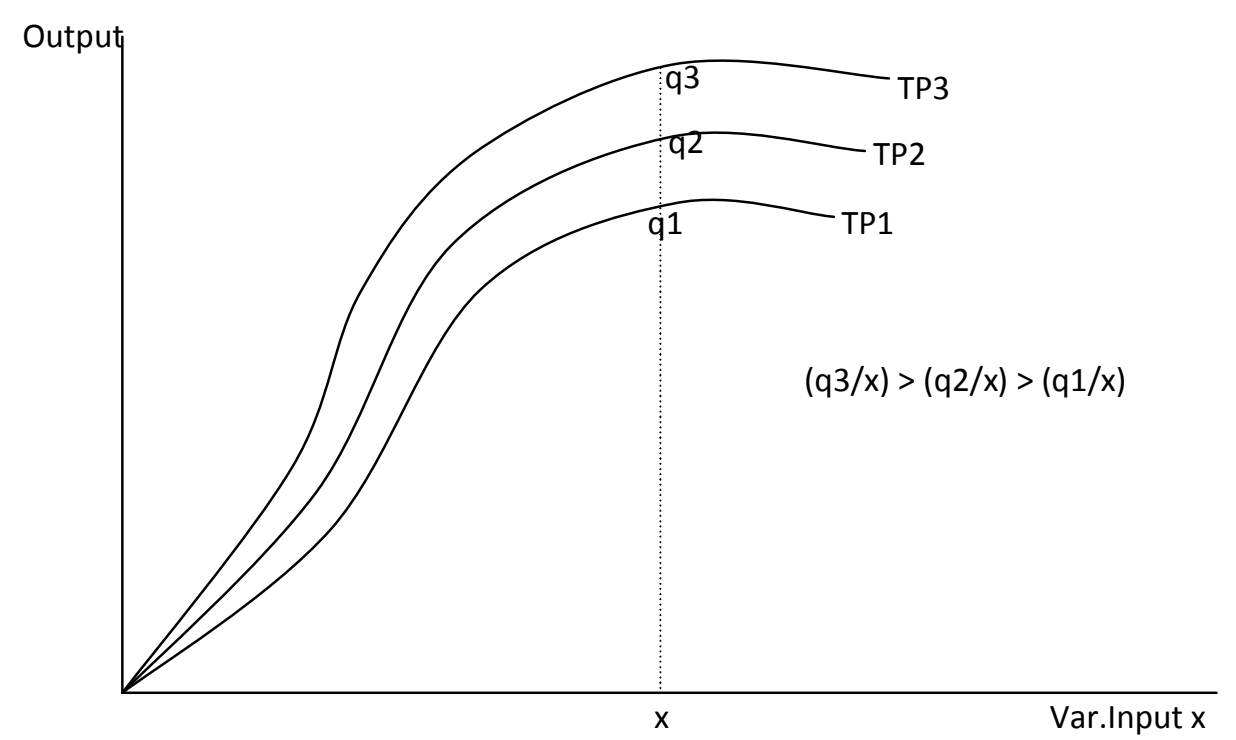

Sumber : Pindyck dan Rubinfeld, 1999 : 137

Gambar 2. Total Produksi dengan Perubahan Teknologi 
Namun studi empiris yang dilakukan lebih dari dua dekade terkahir menunjukkan bahwa modernisasi sumberdaya manusia lebih penting dari sekedar modernisasi mesin, terutama dengan mengubah cara berfikir dan sikap hidup. Dengan modernisasi SDM, kemajuan teknologi akan meresap ke dalam diri manusia (embodied technologi) dan mendorong peningkatan efisiensi (Raharja dan Manurung, 1999 : 141).

Karakteristik fungsi produksi sulit diketahui secara tepat sehingga dilakukan abstraksi ke dalam bentuk yang telah disederhanakan seperti fungsi produksi Cobb-Douglass yang diperluas, dengan banyak input diformulasikan sebagai berikut:

$$
Q=a X_{1}^{b 1} X_{2}^{b 2} \ldots . X_{n}^{b n} e^{u}
$$

dimana $\mathrm{Q}$ adalah jumlah output, a adalah intersep, $\mathrm{b}$ merupakan parameter, $\mathrm{b}_{\mathrm{i}}$ adalah parameter pendugaan peubah ke-i, $X^{i}$ adalah input ke-i, dan $e^{u}$ merupakan disturbance term. Dalam bentuk linier dapat ditulis menjadi:

$$
\ln Q=\ln a+\sum b_{i} \ln X_{i}+u
$$

Jika harga input per unit adalah $r$ dan input variabel adalah $x$ dan karena biaya variabel adalah biaya per unit dari $x$ yaitu $r$ dikali jumlah input tambahan $(\Delta \mathrm{X})$, maka

$$
M C=\frac{\Delta V C}{\Delta Q}=\frac{r d x}{d q}
$$

Dalam jangka panjang seluruh biaya adalah variabel (dapat berubah), karena itu tidak ada biaya yang tetap. Secara matematis, fungsi biaya dapat ditulis:

$$
C=\sum r_{i} x_{i} ; \quad i=1,2,3, \ldots, n
$$

Sedangkan hubungan antara biaya dan produksi dapat ditulis:

$$
C=c\left(q, r_{i}\right)
$$

Dimana $\mathrm{C}=$ biaya total, $\mathrm{r}=$ harga input, $\mathrm{x}=$ input, dan $\mathrm{q}=$ output.

Dalam pasar monopoli besarnya TR sangat tergantung pada besarnya elastisitas harga.

a. Jika elastisitas harga $(\varepsilon)>1$ (elastis), untuk menambah output $1 \%$, harga harus diturunkan lebih kecil dari 1\%, Akibatnya TR naik yang berarti MR positif.

b. Jika $\varepsilon=1$, untuk menambah output $1 \%$ harga harus diturunkan $1 \%$ juga. TR tidak bertambah, yang artinya MR $=0$ dan pada saat ini nilai TR maksimum.

c. Jika $\varepsilon<1$, untuk menaikkan output $1 \%$ harga harus diturunkan lebih dari $1 \%$. TR turun yang artinya MR negatif.

Dalam jangka pendek, analisis untuk memaksimumkan keuntungan dapat dilakukan dengan dua cara (Miller dan Meiners, 1999 : 401) dan (Bilas, 1982 : 294), yaitu pendekatan biaya total (TC) - pendapatan total (TR), dan pendekatan biaya marginal (MC) - pendapatan marginal (MR). 
Pada pendekatan TC-TR, laba maksimum terjadi ketika TC dan TR mempunyai selisih terbesar (TC<TR), secara matematis dapat ditulis seperti pada persamaan (5), dan secara grafis diperlihatkan pada Gambar 3.

$$
\pi=T R(q)-T C(c)
$$

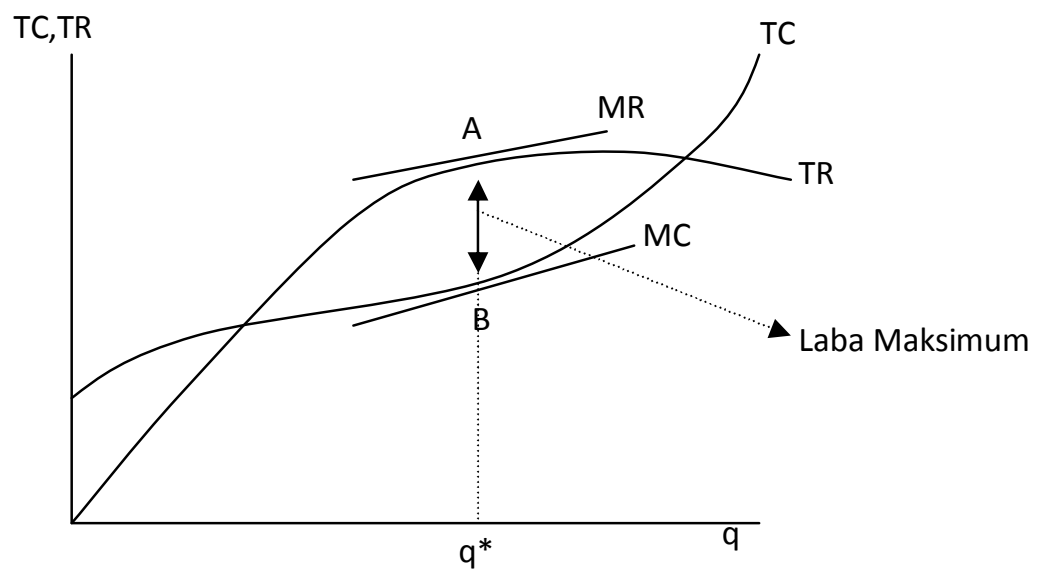

Sumber : Bilas, $1982: 295$

Gambar 3. Daerah Keuntungan Maksimum

Pendekatan biaya MC -MR, diperlihatkan pada Gambar 4. Seperti pada Gambar 3, laba akan mencapai maksimum jika kemiringan kurva TR yaitu MR sama dengan kemiringan kurva TC yaitu MC atau bilamana MR = MC. Hal ini juga dapat dilihat dalam kurva-kuva marginal pada Gambar 4.

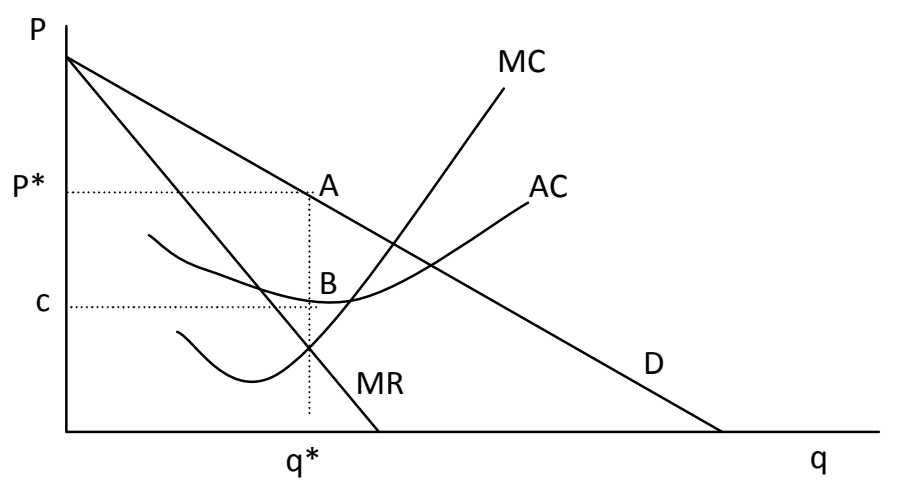

Sumber : Bilas, 1982 : 296.

Gambar 4. Keseimbanan Jangka Pendek

Harga keseimbangan $P^{*}$ ditentukan dari kurva permintaan, sedangkan jumlah keseimbangan ditentukan oleh titik potong MC dan MR. Laba murni diperoleh seluas 
segiempat $A B C P^{*}$. Ini berarti bahwa terdapat laba murni yang maksimum. Jika output dinaikkan dari $\mathrm{q}^{*}$, maka tambahan biaya total (MC) akan lebih besar dari tambahan pendapatan (MR), oleh karena itu laba akan berkurang. Jika output kurang dari $\mathrm{q}^{*}$, akan sebaliknya dan laba belum maksimum karena $\mathrm{MR}>\mathrm{MC}$ sehingga masih memungkinkan untuk menambah output guna menambah laba. Secara matematis ditulis:

$$
\frac{\partial \pi}{\partial q}=\frac{\partial T R}{\partial q}-\frac{\partial T C}{\partial q}
$$

dengan menyamakan ruas kiri dengan nol sebagai syarat perlu, maka diperoleh:

$$
M R=M C \text { (kondisi saat keuntungan maksimum) }
$$

Jika $T R=p q$, maka:

$$
M R=\frac{\partial T R}{\partial q}=\frac{d(p q)}{d q}=q \frac{d p}{d q}
$$

karena elastisitas harga dari permintaan adalah: $\varepsilon=\frac{d q}{d p} \frac{p}{q}$, maka persamaan (8) dapat ditulis menjadi persamaan (9).

$$
M R=p\left(1+\frac{1}{\varepsilon}\right)
$$

Dalam keadaan laba maksimum $M R=M C$, sehingga persamaan (9) dapat ditulis menjadi persamaan (10).

$$
p=M C\left[\frac{\varepsilon}{\varepsilon+1}\right]
$$

Walaupun suatu perusahaan bersifat monopoli, bukan berarti selalu memperoleh laba, dalam jangka pendek bisa saja memperoleh rugi tetapi akan tetap dapat beroperasi asalkan masih dapat menutupi biaya variabel. Dalam jangka panjang, sebuah perusahaan monopoli hanya akan beroperasi jika $p>$ LRAC karena paling sedikit ia harus memperoleh laba normal (normal return on investment).

Penetapan harga output dapat dilakukan dengan beberapa cara, antara lain :

1. Marginalis Pricing, ini dapat dilakukan dengan tiga cara yaitu dengan menggunakan taksiran kurva permintaan dan kurva biaya marginal (marginal cost), taksiran elastisitas harga dan biaya marginal serta menggunakan taksiran biaya dan penerimaan inkremental.

2. Rule-of Thumb Pricing, yang lebih dikenal dengan markup pricing atau cost plus pricing, yaitu penentuan harga melalui penambahan suatu persentase tertentu pada biaya langsung.

3. Marginal Cost Pricing, yaitu penetapan harga pada saat $\mathrm{P}=\mathrm{MC}$. 
4. Average Cost Pricing, yaitu penetapan harga pada saat $\mathrm{P}=\mathrm{AC}$,

Setelah menaikkan harga output, terkadang monopolis masih saja belum mendapatkan laba. Untuk mengatasi kondisi seperti ini ia dapat melakukan "disriminasi harga" (price discrimination), yaitu kebijakan menjual output yang sama dengan harga yang berbeda. Hal ini sering dilakukan oleh PLN, Telkom dan PDAM. Dasar perbedaan harga yang paling sering digunakan adalah dengan melihat siapa konsumennya (elastisitas permintaannya). Permintaan yang lebih elastis dibebankan harga yang lebih rendah dibanding yang inelastis.

Ada beberapa syarat agar diskriminasi harga (berdasarkan elastisitas permintaan) dapat berhasil, yaitu :

1. Perusahaan harus memiliki daya monopoli, karena hanya perusahaan monopoli yang dapat melakukan diskriminasi harga.

2. Pasar dapat dibagi menjadi beberapa (minimal dua kelompok) yang elastisitas permintaannya berbeda.

3. Pembagian pasar harus efektif, artinya tidak memungkinkan terjadinya penjualan kembali dari konsumen yang menikmati harga rendah kepada konsumen yang dibebani harga tinggi.

4. MR di tiap pasar adalah sama agar diskriminasi harga mencapai laba maksimum.

Keuntungan yang diperoleh akibat diskriminsai harga dapat dilihat pada Gambar 5.

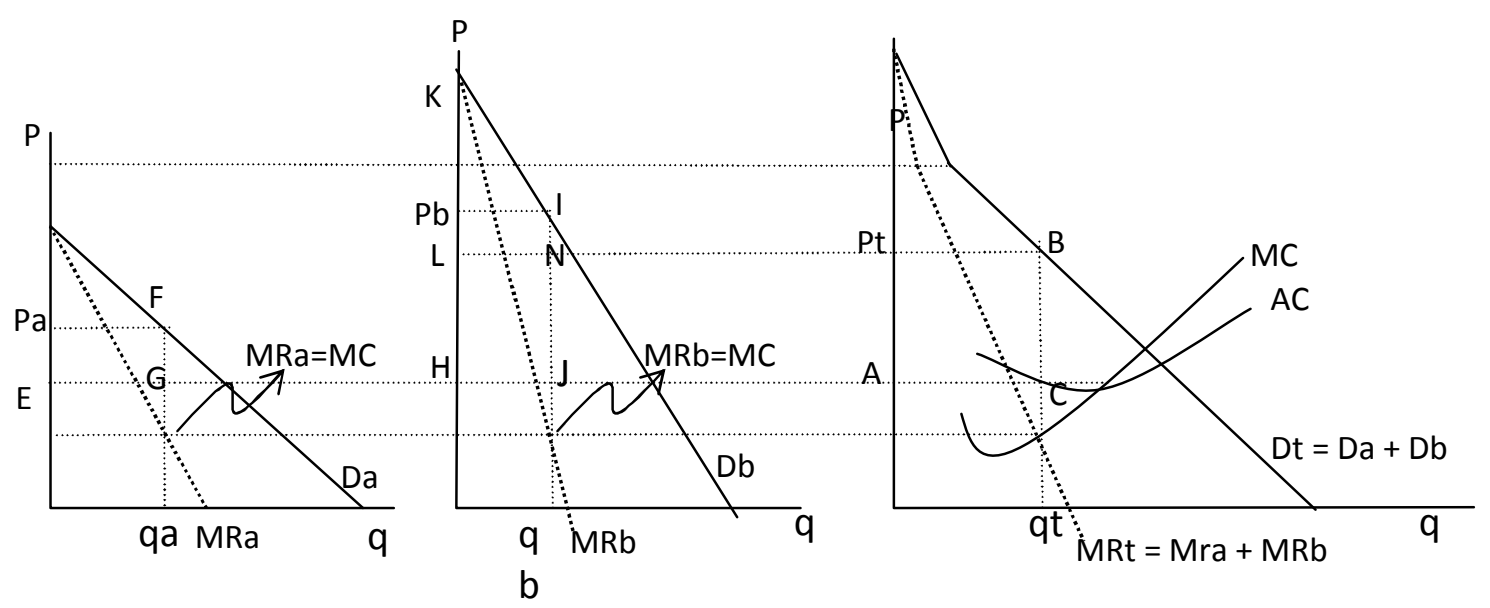

Sumber : Raharja dan Manurung, 1999 : 246

Gambar 5. Diskriminasi Harga

Jika perusahaan tidak melakukan diskriminasi, keseimbangan tercapai pada output qt dengan harga Pt. Laba maksimum diperoleh seluas APtBC. Jika perusahaan melakukan diskriminasi keseimbangan tercapai bila disetiap pasar MR-nya sama dan sama dengan $\mathrm{MC}(\mathrm{MRa}=\mathrm{MRb}=\mathrm{MC})$. Di pasar $\mathrm{A}$, keseimbangan terjadi pada output qa dan harga $\mathrm{Pa}$ 
dengan laba maksimum seluas EPaFG. Di pasar B keseimbangan tercapai pada output $\mathrm{qb}$ dengan harga $\mathrm{Pb}$ dan laba yang diperoleh seluas HPblJ.

Dengan diskriminasi harga output yang terjual sama dengan qa $+q b$, tetapi laba maksimum yang diperoleh lebih besar dari pada tidak melakukan diskriminasi. Tambahan laba diperoleh dengan mengeksploitasi surplus konsumen yang permintaannya inelastis.

Penggolongan diskriminasi harga tergantung pada derajat diskriminasinya. Menurut A.C.Pigou dalam bukunya The Economics of Welfare (1920) pada Arsyad (1999 : 340), (Varian, 1999 : 434), (Varian, 1992 : 241) derajat diskriminasi dibagi atas tiga bagian, yaitu :

1. Diskriminasi harga derajat ketiga (third-degree price discrimination), dimana pembeli dibedakan menjadi kelas-kelas berdasarkan kadar elastisitas permintaannya, permintaan yang lebih elastis akan dikenai harga yang lebih murah dan sebaliknya.

2. Diskriminasi harga derajat kedua (second-degree price discrimination), yaitu pembedaan harga yang didasarkan pada banyak sedikitnya jumlah pembelian.

3. Diskriminasi harga tingkat pertama (first-degree discrimination), yaitu dengan mengenakan harga maksimal yang mampu dibayar konsumen untuk setiap produk yang dibeli.

Karena besarnya kekuasaan monopolis dalam pasar, maka pemerintah perlu ikut campur dalam penetapan harga output agar monopoli dapat diarahkan untuk meningkatkan kesejahteraan rakyat. Hal ini dapat dilakukan dengan beberapa cara diantaranya mengambil kebijakan penetapan harga tertinggi (ceiling price) bagi perusahaan monopoli. Monopolis tidak diperkenankan menjual output di atas harga tertinggi dan jika hal itu terjadi maka pemerintah dapat mengenakan sanksi.

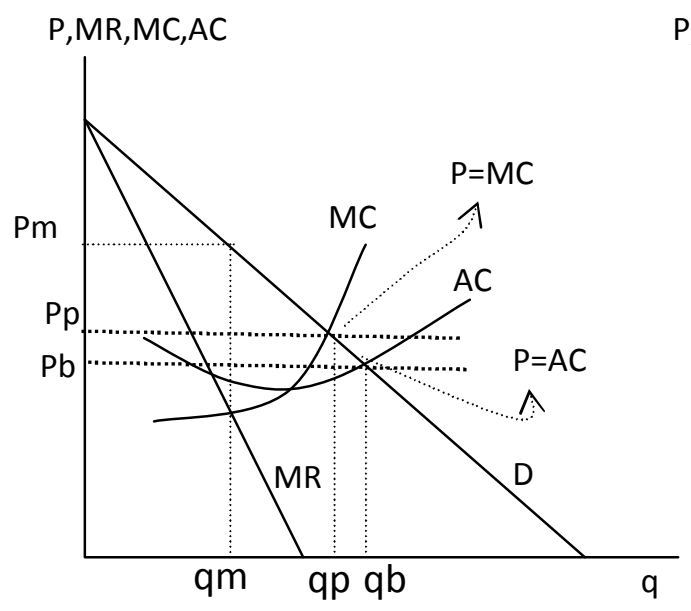

(A)

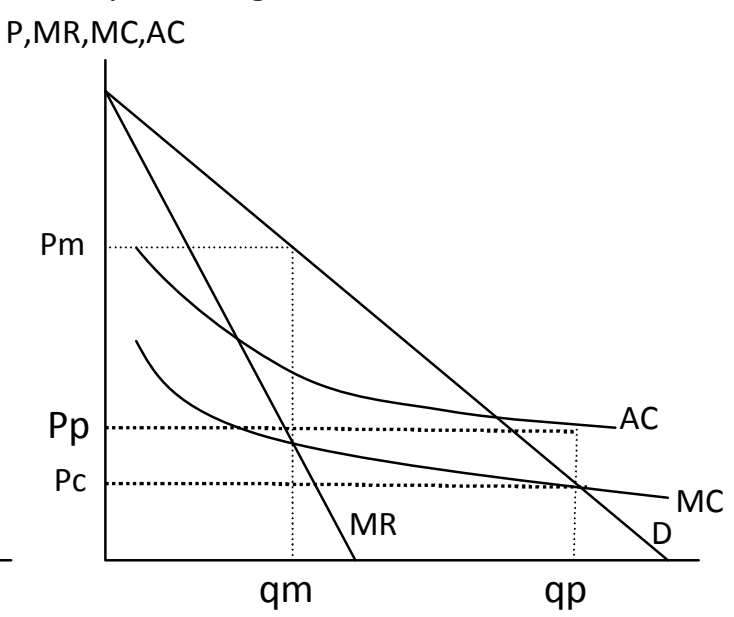

(B)

Sumber : Koutsoyiannis,1985:201; Raharja dan Manurung, 1999

Gambar 6. Kebijakan Pengaturan Harga pada Pasar Monopoli 
Jika monopolis menetapkan harga sebesar Pm (pada saat laba maksimum, MR=MC), dan menjual output sebanyak qm, pemerintah dapat menetapkan patokan harga sebesar $\mathrm{Pp}$ (saat $\mathrm{MC}=\mathrm{P}$ ) dengan tingkat output $\mathrm{qp}$, dan monopolis masih memperoleh keuntungan di atas normal. Atau bahkan pemerintah dapat menetapkan harga yang lebih rendah lagi, yaitu sebesar $\mathrm{Pb}$ dengan output $\mathrm{qb}$ (padaa saat $\mathrm{P}=\mathrm{AC}$ ) dan keuntungan yang diperoleh adalah keuntungn normal, sehingga kesejahteraan rakyat dapat meningkat. Demikian juga untuk monopolis alamiah seperti pada Gambar 6 (B).

Andaikan pada diskriminasi harga derajat ketiga, $\mathrm{p}_{1}\left(\mathrm{y}_{1}\right)$ dan $\mathrm{p}_{2}\left(\mathrm{y}_{2}\right)$ adalah inverse demand curves untuk pasar 1 dan pasar $2, \mathrm{c}\left(\mathrm{y}_{1}+\mathrm{y}_{2}\right)$ adalah total biaya produksi, maka persoalan yang dihadapi adalah (Varian,1987 : 440-441) :

$$
\max p_{1}\left(y_{1}\right)+p_{2}\left(y_{2}\right)-c\left(y_{1}+y_{2}\right)
$$

pemecahan optimal dicapai bila :

$$
\begin{aligned}
& M R_{1}\left(y_{1}\right)=\operatorname{MC}\left(y_{1}+y_{2}\right) \\
& M R_{2}\left(y_{2}\right)=\operatorname{MC}\left(y_{1}+y_{2}\right)
\end{aligned}
$$

Ini berarti bahwa MR dari tambahan satu unit produksi harus sama dengan MR di setiap pasar. Jika formula elastisitas ditulis dalam bentuk maksimisasi keuntungan, yaitu :

$$
\begin{aligned}
& p_{1}\left(y_{1}\right)\left[1-\left(\frac{1}{\varepsilon\left(y_{1}\right.}\right)\right]=M C\left(y_{1}+y_{2}\right), \text { dan } \\
& p_{2}\left(y_{2}\right)\left[1-\left(\frac{1}{\varepsilon\left(y_{2}\right.}\right)\right]=M C\left(y_{1}+y_{2}\right)
\end{aligned}
$$

dimana $\varepsilon\left(\mathrm{y}_{1}\right)$ dan $\varepsilon\left(\mathrm{y}_{2}\right)$ merupakan elastisitas permintaan dari masing-masing pasar. Pasar yang tingkat elastisitasnya lebih besar harus memiliki harga yang lebih rendah.

\section{PEMBAHASAN}

Andaikan fungsi produksi yang digunakan adalah fungsi produksi Cobb-Douglas.

$$
Q=a X_{1}^{b 1} X_{2}^{b 2} \ldots . X_{n}^{b n} e^{u}
$$

dan, misalkan jumlah variabel bebas yang digunakan adalah 5 variabel, maka fungsi produksinya menjadi:

$$
Q=a X_{1}^{b 1} X_{2}^{b 2} X_{3}^{b 3} X_{4}^{b 4} X_{5}^{b 5} e^{u}
$$

Persamaan (15) dapat diubah ke dalam bentuk linier dengan mengambil logaritma dari kedua ruas persamaan.

$$
\ln Q=\ln a+b_{1} \ln x_{1}+b_{2} \ln x_{2}+b_{3} \ln x_{3}+b_{4} \ln x_{4}+b_{5} \ln x_{5}+u
$$


Model minimisasi biaya terhadap fungsi produksi Cobb-Douglas, dengan fungsi tujuan adalah meminimumkan biaya:

$$
C=\sum r_{i} x_{i}=r_{i} \mathrm{x}_{\mathrm{i}}+r_{j} x_{j} ; \quad i, j=1,2,3,4,5
$$

dengan kendala:

$$
q=q\left(x_{i}\right)=a x_{i}^{b i} x_{j}^{b j}
$$

sehingga fungsi objektif menjadi:

$$
Z=\sum r_{i} x_{i}+\lambda\left[q-q\left(x_{i}\right)\right]=r_{i} x_{i}+r_{j} x_{j}+\lambda\left[q-a x_{i}^{b i} x_{j}^{b j}\right]
$$

Dengan, $C$ : total biaya, $r_{\mathrm{i}}$ harga input ke-i, $x_{\mathrm{i}}$ : jumlah input ke-i, $\mathrm{Z}$ : fungsi tujuan atau fungsi objektif, dan $q$ : output.

Syarat order pertama:

$$
\begin{aligned}
\frac{\partial Z}{\partial x_{i}} & =r_{i}-\lambda q\left(x_{i}\right)=0 \\
& =r_{i}-\lambda a b_{i} x_{i}^{b i-1} x_{j}^{b j}=0 \\
\frac{\partial Z}{\partial x_{j}} & =r_{j}-\lambda a b_{j} x_{i}^{b i} x_{j}^{b j-1}=0 \\
\frac{\partial Z}{\partial \lambda} & =q-a x_{i}^{b i} x_{j}^{b j}=0
\end{aligned}
$$

dari (21) dan (22) diperoleh:

$$
\begin{aligned}
\frac{r_{i}}{r_{j}} & =\frac{b_{i} x_{i}^{b i-1} x_{j}^{b j}}{b_{j} x_{i}^{b i} x_{j}^{b j-1}} \\
& =\frac{b_{i} x_{j}}{b_{j} x_{i}}, \text { atau } x_{j}=\left(\frac{b_{j} r_{i}}{b_{i} r_{j}}\right) x_{i}
\end{aligned}
$$

Persamaan (24) disebut juga dengan jalur ekspansi. Jika jalur ekspansi yang diperoleh pada persamaan (24) disubstitusikan ke fungsi produksi, maka akan diperoleh persamaan permintaan input kodisional (conditional input demand), yaitu:

$$
\begin{gathered}
q-a x_{i}^{b i}\left[\left(\frac{b_{j} r_{i}}{b_{i} r_{j}}\right) x_{i}\right]^{b j}=0 \\
q=a x_{i}^{b i+b j}\left[\left(\frac{b_{j} r_{i}}{b_{i} r_{j}}\right)\right]^{b j} \\
x_{i}^{b i+b j}=\frac{q}{a\left(b_{j} r_{i} / b_{i} r_{j}\right)^{b j}}
\end{gathered}
$$


Misalkan $\Sigma b=\gamma$, maka:

$$
\begin{aligned}
& x_{i}^{\gamma}=\frac{q}{a\left(b_{j} r_{i} / b_{i} r_{j}\right)^{b j}} \\
& x_{i}=\left[\frac{q}{a\left(b_{j} r_{i} / b_{i} r_{j}\right)^{b j}}\right]^{\frac{1}{\gamma}} \\
& x_{i}=q^{\frac{1}{\gamma}} a^{-\frac{1}{\gamma}} b_{i}^{\frac{b j}{\gamma}} b_{j}^{-\frac{b j}{\gamma}} r_{i}^{-\frac{b j}{\gamma}} r_{j}^{-\frac{b j}{\gamma}} \\
& x_{i}=q^{1 / \gamma} a^{-1 / \gamma} b_{i}^{(\gamma-b i) / \gamma} b_{j}^{-b j / \gamma} r_{i}^{-(\gamma-b j) / \gamma} r_{j}^{b j / \gamma}
\end{aligned}
$$

sehingga untuk $i=1,2,3,4,5 ; j=1,2,3,4,5 ; \mathrm{i} \neq \mathrm{j}$, diperoleh permintaan input kondisional untuk:

$$
\begin{aligned}
& x_{1}=q^{1 / v} a^{-1 / v} b_{1}{ }^{(\gamma-b 1) / v} b_{2}{ }^{-b 2 / v} b_{3}{ }^{-b 3 / v} b_{4}{ }^{-b 4 / v} b_{5}{ }^{-b 5 / v} r_{1}{ }^{-(\gamma-b 1) / v} r_{2}{ }^{b 2 / v} r_{3}{ }^{b 3 / v} r_{4}{ }^{b 4 / v} r_{5}{ }^{b 5 / v} \\
& x_{2}=q^{1 / v} a^{-1 / v} b_{2}{ }^{(1-b 2) / v} b_{1}{ }^{-b 1 / v} b_{3}{ }^{-b 3 / v} b_{4}{ }^{-b 4 / v} b_{5}{ }^{-b 5 / v} r_{2}{ }^{-(\gamma-b 2) / v} r_{1}{ }^{b 1 / v} r_{3}{ }^{b 3 / v} r_{4}{ }^{b 4 / v} r_{5}{ }^{b 5 / v} \\
& x_{3}=q^{1 / v} a^{-1 / v} b_{3}{ }^{(\nu-b 3) / v} b_{1}{ }^{-b 1 / v} b_{2}{ }^{-b 2 / v} b_{4}{ }^{-b 4 / v} b_{5}{ }^{-b 5 / v} r_{3}{ }^{-(\gamma-b 3) / v} r_{1}{ }^{b 1 / v} r_{2}{ }^{b 2 / v} r_{4}{ }^{b 4 / v} r_{5}{ }^{b 5 / v} \\
& x_{4}=q^{1 / v} a^{-1 / v} b_{4}{ }^{\left(\gamma^{-b} 4\right) / v} b_{1}{ }^{-b 1 / v} b_{2}{ }^{-b 2 / v} b_{3}{ }^{-b 3 / v} b_{5}{ }^{-b 5 / v} r_{4}{ }^{-(\gamma-b 4) / v} r_{1}{ }^{b 1 / v} r_{2}{ }^{b 2 / v} r_{3}{ }^{b 3 / v} r_{5}{ }^{b 5 / v} \\
& x_{5}=q^{1 / v} a^{-1 / v} b_{5}{ }^{\left({ }^{-b 5) / v}\right.} b_{1}{ }^{-b 1 / v} b_{2}{ }^{-b 2 / v} b_{3}{ }^{-b 3 / v} b_{4}{ }^{-b 4 / v} r_{5}{ }^{-(\gamma-b 5) / v} r_{1}{ }^{b 1 / v} r_{2}{ }^{b 2 / v} r_{3}{ }^{b 3 / v} r_{4}{ }^{b 4 / v}
\end{aligned}
$$

Syarat order kedua: $\frac{\partial^{2} Z}{\partial x^{2}{ }_{i}}>0$

Jika persamaan (27) hingga persamaan (31) disubstitusikan ke fungsi biaya langsung yaitu persamaan (18), akan diperoleh fungsi biaya tidak langsung (Indirect Cost Function), yaitu:

$$
\begin{aligned}
\mathrm{C}= & q^{1 / v} a^{-1 / v} r_{1}{ }^{b 1 / v} r_{2}{ }^{b 2 / v} r_{3}{ }^{b 3 / v} r_{4}{ }^{b 4 / v} r_{5}{ }^{b 5 / v}\left[\left(b_{1} / b_{2}\right)^{b 2 / v}\left(b_{1} / b_{3}\right)^{b 3 / v}\left(b_{1} / b_{4}\right)^{b 4 / v}\left(b_{1} / b_{5}\right)^{b 5 / v}\right. \\
& +\left(b_{2} / b_{1}\right)^{b 1 / v}\left(b_{2} / b_{3}\right)^{b 3 / v}\left(b_{2} / b_{4}\right)^{b 4 / v}\left(b_{2} / b_{5}\right)^{b 5 / v}+\left(b_{3} / b_{1}\right)^{b 1 / v}\left(b_{3} / b_{2}\right)^{b 2 / v} \\
& \left(b_{3} / b_{4}\right)^{b 4 / v}\left(b_{3} / b_{5}\right)^{b 5 / v}+\left(b_{4} / b_{1}\right)^{b 1 / v}\left(b_{4} / b_{2}\right)^{b 2 / v}\left(b_{4} / b_{3}\right)^{b 3 / v}\left(b_{4} / b_{5}\right)^{b 5 / v}+\left(b_{5} / b_{1}\right)^{b 1 / v} \\
& \left.\left(b_{5} / b_{2}\right)^{b 2 / v}\left(b_{5} / b_{3}\right)^{b 3 / v}\left(b_{5} / b_{4}\right)^{b 4 / v}\right]
\end{aligned}
$$

misalkan,

$$
\begin{aligned}
A= & a^{-1 / v}\left[\left(b_{1} / b_{2}\right)^{b 2 / v}\left(b_{1} / b_{3}\right)^{b 3 / v}\left(b_{1} / b_{4}\right)^{b 4 / v}\left(b_{1} / b_{5}\right)^{b 5 / v}+\left(b_{2} / b_{1}\right)^{b 1 / v}\left(b_{2} / b_{3}\right)^{b 3 / v}\right. \\
& \left(b_{2} / b_{4}\right)^{b 4 / v}\left(b_{2} / b_{5}\right)^{b 5 / v}+\left(b_{3} / b_{1}\right)^{b 1 / v}\left(b_{3} / b_{2}\right)^{b 2 / v}\left(b_{3} / b_{4}\right)^{b 4 / v}\left(b_{3} / b_{5}\right)^{b 5 / v}+ \\
& \left(b_{4} / b_{1}\right)^{b 1 / v}\left(b_{4} / b_{2}\right)^{b 2 / v}\left(b_{4} / b_{3}\right)^{b 3 / v}\left(b_{4} / b_{5}\right)^{b 5 / v}+\left(b_{5} / b_{1}\right)^{b 1 / v}\left(b_{5} / b_{2}\right)^{b 2 / v} \\
& \left.\left(b_{5} / b_{3}\right)^{b 3 / v}\left(b_{5} / b_{4}\right)^{b 4 / v}\right],
\end{aligned}
$$

maka persamaan (15) dapat ditulis menjadi:

$$
\mathrm{C}=A q^{1 / v} r_{1}{ }^{b 1 / v} r_{2}{ }^{b 2 / v} r_{3}{ }^{b 3 / v} r_{4}{ }^{b 4 / v} r_{5}{ }^{b 5 / v}
$$

Misalkan, $\vartheta_{1}=1 / \gamma ; \vartheta_{2}=\mathrm{b} 1 / \mathrm{\gamma} ; \vartheta_{3}=\mathrm{b} 2 / \mathrm{\gamma} ; \vartheta_{4}=\mathrm{b} 3 / \mathrm{\gamma} ; \vartheta_{5}=\mathrm{b} 4 / \mathrm{\gamma}$; dan $\vartheta_{5}=\mathrm{b} 5 / \mathrm{\gamma}$, maka persamaan (33) dapat ditulis menjadi persamaan (34). 


$$
C=A q^{\theta 1} r_{1}^{\theta 2} r_{2}^{\theta 3} r_{3}^{\theta 4} r_{4}^{\theta 5} r_{5}^{\theta 6}
$$

Dalam bentuk linier, persamaan (34) dapat ditulis menjadi persamaan (35).

$$
\ln C=\ln A+\theta 1 \ln q+\theta 2 \ln r_{1}+\theta 3 \ln r_{2}+\theta 4 \ln r_{3}+\theta 5 \ln r_{4}+\theta 6 \ln r_{5}
$$

Merupakan persamaan indirect cost function yang dapat diestimasi menggunakan OLS, dengan $C$ adalah total biaya input, $r 1, . . r 5$ merupakan variabel bebas yang menentukan biaya produksi. Biaya rata-rata dari produksi ini diperlihatkan pada persamaan (36).

$$
A C=A \cdot q^{\theta 1-1} r_{1}{ }^{\theta 2} r_{2}{ }^{\theta 3} r_{3}{ }^{\theta 4} r_{4}{ }^{\theta 5} r_{5}{ }^{\theta 6}
$$

dan biaya marginal:

$$
M C=\frac{\partial C}{\partial q}=\theta_{1} \cdot A C
$$

Bentuk fungsi biaya dan keadaan return to scale dapat dilihat dari $\Sigma \vartheta_{\mathrm{i}}$, bila $\Sigma \vartheta_{\mathrm{i}}>1$, fungsi biaya adalah strictly concave, yang berarti $A C>M C$ dimana $A C$ dan $M C$ menurun dan berada dalam keadaan increasing return to scale. Bila $\Sigma \vartheta_{i}<1$, fungsi biaya adalah strictly convex, yang berarti $A C<M C$ dimana $A C$ dan $M C$ menaik dan berada dalam keadaan decreasing return to scale. Bila $\Sigma \vartheta_{\mathrm{i}}=1$, fungsi biaya adalah linear, yang berarti $A C=M C$ serta $A C$ dan $M C$ konstan dan berada dalam keadaan constant return to scale. (Koutsoyiannis,1985:77 ; Arsyad,1999:246). Selanjutnya fungsi biaya tidak langsung yang telah diestimasi diderivasi dengan metode Shephard's lemma $\left(\delta C / \delta r_{i}\right)$ untuk mendapatkan fungsi permintaan input masing-masing variabel (conditional input demand).

Skala produksi tersebut juga dapat dianalisis dari elastisitas biaya terhadap output $\left(E_{\mathrm{c}}\right)$, dimana:

$$
E_{\mathrm{C}}=(\Delta \mathrm{C} / \Delta \mathrm{Q}) /(\mathrm{C} / \mathrm{Q})=\mathrm{MC} / \mathrm{AC}
$$

Jika $E_{c}<1$, produksi berada pada skala ekonomis (economies of scale) hal ini mencerminkan biaya akan meningkat lebih lambat daripada output. Jika $E_{c}>1$, produksi berada pada skala yang tidak ekonomis, hal ini mencerminkan bahwa setiap kenaikan output akan menyebabkan kenaikan biaya yang lebih besar (Pindyck dan Rubinfeld, 1999: 164; Arsyad, 1999:267).

Pada perusahaan monopoli keuntungan maksimum diperoleh pada saat $M R=M C$ dan perusahaan akan memperoleh laba super normal. Oleh sebab itu untuk menghindari harga output yang terlalu tinggi pemerintah dapat ikut campur dengan menetapkan harga output per unit pada saat harga $(P)$ sama dengan biaya rata-rata $(A C)$, atau $P=$ $A C$. Setelah fungsi biaya diketahui, harga yang seharusnya di setiap pasar dapat diperoleh dengan membandingkan laba disetiap pasar.

\section{KESIMPULAN}

Penentuan tarif suatu industri monopoli, khususnya industri penyedia barang publik yang dikelola oleh pemerintah untuk kepentingan masyarakat,secara teori dapat 
dihitung dari sisi biaya yang dikeluarkan untuk melakukan produksi. Fungsi biaya dapat diestimasi dengan meminimumkan biaya, dengan kendala fungsi produksi, dan akhirnya akan diperoleh indirect cost function. Oleh karena itu, fungsi produksi dari industri tersebut harus diketahui terlebih dahulu. Dari turunan fungsi biaya tidak langsung tersebut dapat diketahui biaya rata-rata dan biaya marginal yang selanjutnya digunakanuntuk menentukan harga.

\section{DAFTAR PUSTAKA}

Arsyad, Lincolin, 1999. Ekonomi Mikro Manajerial : Ekonomi Mikro Terapan Untuk Manajemen Bisnis, BPFE Yokyakarta, Yokyakarta.

Bilas, Richard A, 1982. Ekonomi Mikro, terjemahan Djoerban Wahid, Erlangga, Jakarta.

Henderson, James M. and Richard E.Quandt, 1980. Microeconomic Theory : A Mathematical Approach, Third edition, McGraw-Hill Book Co., Singapore.

Koutsoyiannis,A, 1985. Modern Microeconomics, Second edition, Macmillan Publishers Ltd, London.

Miller R.L dan Meiners R.E, 1994. Teori Ekonomi Mikro Intermediate, terjemahan Haris Munandar, PT.RajaGrafindo Persada, Jakarta.

Nicholson, Walter, 1992, Mikro Ekonomi Intermediate dan Penerapannya, terjemahan Danny Hutabarat, Erlangga, Jakarta.

Pindyck, Robert S. dan D.L.Rubinfeld, 1999, Mikro Ekonomi, terjemahan Aldi Jenie, PT.Prenhallindo, Jakarta.

Raharja P. dan Manurung M., 1999. Teori Ekonomi Mikro : Suatu Pengantar, FE UI, Jakarta.

Varian, Hal.R, 1992. Microeconomic Analisys Third Edition, W.W.Norton \& Company,Inc, New York.

Salvatore, Dominick, 2002, Managerial Economic : Dalam Perekonomian Global, Edisi keempat, terjemahan M.Th.Anitawati dan Natalia Santoso, Erlangga, Jakarta.

Varian, Hal.R, 1999, Intermediate Microeconomic : A Modern Approach Fifth Edition, W.W.Norton \& Company,Inc.,New York. 